\title{
Sobre a divulgação e recepção da literatura brasileira na Hungria
}

\author{
Ferenc Pál \\ Professor Emeritus da Eötvös Loránd University.
}

As primeiras informações da literatura brasileira chegam ao público húngaro por via dos verbetes das enciclopédias editadas na viragem dos séculos XIX e XX. N’A Grande Enciclopédia da Pallas ${ }^{1}$ alguns poetas destacados (como Gonçalves de Magalhães, Gonçalves Dias e Tomás António de Gonzaga) já tem verbetes autónomos. No volume 3, de 1911, da Grande Enciclopédia da Révai já se encontra um verbete em separado sobre a "literatura brasiliana", rezando que "a literatura brasiliana durante muito tempo foi apenas um ramo da literatura portuguesa e só nos últimos tempos começou a se desenvolver em rumo diferente". Nesta enciclopédia já aumenta o número dos autores com verbete autónomo (assim encontramos incluídos nela os mais importantes ou famosos autores do romantismo, como Macedo, Álvares de Azevedo, Bernardo Guimarães, etc.). Nas enciclopédias posteriores, em especial nas enciclopédias de literatura universal ${ }^{3}$, encontramos informações cada vez mais sofisticadas da literatura brasileira, até que na volumosa Enciclopédia da Literatura Universal, cujos volumes saíam desde 1970 até meados dos $1990^{4}$, encontramos, além dos verbetes sobre a literatura brasileira e fenómenos literários ligados com o Brasil (como por ex.: o Modernismo), verbetes de 228 escritores brasileiros.

Mas tudo isto é apenas uma mera informação das letras brasileiras que ainda não é acompanhada de obras traduzidas para conhecimento do público húngaro. A primazia, segundo hoje podemos afirmar, corresponde a um conto de Machado de Assis, que foi

1 A Pallasz Nagy Lexikona.

2 Révai Nagy Lexikona.

3 Queremos mencionar, apenas como contribuição bibliográfia, as enciclopédias da literatura seguintes, mencionadas na bibliografia: Irodalmi Lexikon, Világirodalmi Lexikon, Világirodalmi Kisenciklopédia

4 Világirodalmi Lexikon.

Gláuks: Revista de Letras e Artes - jul/dez 2020 - v. 20, n. 2 


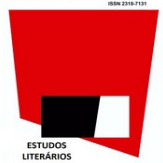

publicado em 1912 num jornal de Budapeste, Világ, com o título Az ápolós. Se trata de uma publicação um pouco desleixada porque não aparece nem o nome do autor nem o do tradutor. A segunda tradução em húngaro de um autor brasileiro é um conto de Monteiro Lobato que saiu na revista ilustrada da literatura e artes, intitulada Pásztortüz, editada em Transilvânia ${ }^{6}$. O conto $A z$ élcfaragó ('Fabricante de piadas') sai na secção "Narradores Estrangeiros” e é acompanhado de uma nota biográfica. ${ }^{7}$

Estas publicações esporádicas não formaram uma "imagem literária" do Brasil, nem conseguiram colocar a literatura brasileira no contexto da literatura húngara. A primeira tentativa de uma aproximação consciente, com fins de encontrar uma comunicação com as letras brasileiras, acontece no final da década de 1930, com a atividade, trabalhos realizados do tradutor Paulo Rónai e do publicista György Bálint.

Paulo Rónai ${ }^{8}$ compôs e traduziu uma seleção de poemas, intitulada Brazília üzen ('Mensagem do Brasil'), publicada em 1939. Este livrinho, que tem poemas de 25 poetas brasileiros $^{9}$ da primeira metade do século XX e uma introdução que esboça o panorama da literatura brasileira, é uma publicação de amplas visões que lança os alicerces para um conhecimento ulterior. Rónai, no prefácio, apresenta a poesia brasileira como uma manifestação "de um jovem povo com cultura, enérgico e em vias de desenvolvimento que vive uma vida intelectual cada vez mais profunda" ${ }^{10}$, mas, ao mesmo, tempo rejeita satisfazer um gosto pelo exótico ou movido por um interesse folclórico. Desta o selecionador dá uma preferência aos poemas de alto quilate poético, um pouco universalizante e relega para

5 “Az ápoló” ('O enfermeiro'). Világ, ano III. Nro. 46. 23 de fevereiro de 1912, sexta-feira: 1 e 2, na secção do folhetim. Sem indicação do nome do tradutor.

6 Az élcfaragó. In: Pásztortüz (Kolozsvár/Cluj), ano XVI. Nro. 17. 24 de agosto de 1930: 391-393. Sem nome completo do tradutor, indicado apenas com a abreviação: Szys.

7 Esta nota diz entre outras coisas: "Monteiro Lobato é o criador da moderna literatura nacional no Brasil. Tem por objetivo a compensação da literatura gálica e ao mesmo tempo o descobrimento das enfermidades da alma brasileira..." A apresentação avaliativa do autor faz-nos supor que é trabalho de uma pessoa conhecedora da literatura brasileira e mostra a seriedade desta revista que reunia uma série de escritores da Transilvânia da época.

8 Para os poucos que não conheçam o nome dele, dizemos que Paulo Rónai (1907-1992) é um literato húngaro que em 1940 trasladou-se para o Brasil como bolseiro do governo brasileiro e nesta sua nova pátria desenvolveu variada atividade como tradutor, crítico e historiador de literatura. O mencionado livro foi editado em 1939, Budapeste, por Vajda János Társaság. 9 Aristeo Seixas, Menotti del Picchia, Olavo Bilac, Alberto de Oliveira, Manuel Carlos, Pedro Saturnino, Correa Junior, Cruz e Sousa, Cecilia Meirelles, Francisco Karam, Ribeiro Couto, Manuel Bandeira, Adalgisa Nery, Augusto de Almeida Filho, Vicente de Carvalho, Cassiano Ricardo, Paulo Setubal, Mario de Andrade, Jorge de Lima, Lobivar Matos, Ronald de Carvalho, Tasso da Silveira, Carlos Drummond de Andrade, Augusto Frederico Schmidt. (os nomes aparecem na forma como apareciam no edição húngara). 10 Rónai 1939: 8.

Gláuks: Revista de Letras e Artes - jul/dez 2020 - v. 20, n. 2 
segundo plano aqueles que em versos desiguais e livres apresentem cores e tons mais ásperos, mais modernos, como por exemplo os de Ronald de Carvalho sobre o Brasil. ${ }^{11}$ Assim, dos 33 poemas do livro, reunidos em quatro pequenos ciclos, só 7 a 8 do ciclo "Descobrimento do Brasil" evocam cores tipicamente brasileiras.

Este princípio da escolha e apresentação dos poemas resultou do gosto intelectual urbano daquele então, pois a abertura para horizontes fora da Europa e o gosto pelo exótico só advém depois da Segunda Grande Guerra. É esta mesma voz universal e não as peculiaridades exóticas, estranhas, que se frisa na recensão informativo-crítica do publicista György Bálint, escrita alguns meses depois da publicação do livro de poemas de Paulo Rónai ${ }^{12}$.

Os livros de viagens ou os folhetos turísticos mostram só o exotismo, entretanto que os poetas informam sobre o essencial. Este essencial, este "outro Brasil" o encontramos neste livro de traduções novo e belo. [...] todos os poetas são parentes, afinal, a mesma coisa dóilhes ou alegra os poetas criolos, negros, índios e mestiços que os franceses ou húngaros. Mesmo a sua voz é afim e universal...

Nestas palavras do publicista, escritas na véspera da Grande Guerra, percebe-se também uma preocupação pelos valores da cultura ameaçados, assim, as suas palavras sobre a poesia brasileira têm uma mensagem política para a atualidade de então ${ }^{13}$. Esta mesma posição se reflete num outro texto dele ${ }^{14}$, escrito depois da leitura, em francês, do Dom Casmurro, de Machado de Assis, que ele apresenta como romance por excelência, quase como "instituição nacional”.

O publicista que, segundo diz, se familiarizara com o Brasil pela leitura das traduções de Paulo Rónai ${ }^{15}$ chega a conclusão, um pouco precipitada (e já sabemos, falsa), que os

11 Notamos, por outro lado, uma falta total de poemas da primeira fase do movimento modernista, que, parece, não correspondiam ao gosto do selecionador. Esta mesma antipatia pela literatura da vanguarda ou/e experimental também se nota, muito mais tarde, na sua colaboração para a Enciclopédia da Literatura Universal, onde, por exemplo, não aparecem os representantes da poesia concreta etc. Não sejamos, contudo, injustos com Paulo Rónai, ele neste prefácio citado fala sobre as dificuldades de obter livros do Brasil: pode ser que simplesmente não tinha ao alcance de mão todas as obras necessárias para uma antologia equilibrada.

12 "Brazilia üzen" ('Mensagem do Brasil'). Magyarország, 2 de outubro de 1939. Nro. 225: 7.

13 É com estas palavras que se acaba o texto: "Agora desde escrivaninhas brasileiras, mãos brancas ou negras batem o sinal tranquilizador, dizendo que estão de guarda e da Europa maltratada bate-se a resposta: "Obrigado".

14 Braziliai regény ('Romance brasiliense'). In: Pesti Napló, 30 de julho de 1939. Nro. 172: 31.

15 Para os leitores mais sagazes, que pensam descobrir uma incongruência de datas, assinalamos que o publicista pôde ler as traduções de Paulo Rónai antes da publicação do livro Mensagem do Brasil, em agosto de 1939, porque o tradutor publicara algumas delas em diferentes revistas, anteriormente.

Gláuks: Revista de Letras e Artes - jul/dez 2020 - v. 20, n. 2 
brasileiros são gente feliz porque têm esta preferência pela literatura pura que não se ocupa de problemas nacionais e não fala sobre problemas trágicos da nação, como por exemplo afirma ele - a literatura húngara. Suas palavras novamente refletem uma perspectiva universalizante, porque ele sublinha que o maior mérito deste livro é que não é "nada brasileiro": "Não tem nada de exótico, a não ser que os criados sejam negros e um dos amigos do personagem principal tenha lepra."

É curioso a falta de sensibilidade, nesta época estudada, para o exotismo, ou pelo menos, para os problemas específicos do Brasil, que tanto determinou depois a visão da geração que tinha conhecimento das letras latino-americanas, incluindo as brasileiras, através dos escritores do "boom". Hei de notar isso porque numa outra recensão crítica intitulada Brazilia üzen ('Mensagem do Brasil'), que saiu na revista literária Nyugat ${ }^{16}$, o autor da mesma escreve: "não procuremos um exotismo exterior na poesia" e acrescenta "porque além dos poemas acostumados, que deixam entrever uma influência francesa, encontramos, neste livro, alguns poemas de pompa estranha e surpreendentes. O estranho não se diz com respeito ao couleur locale... “. Os poemas caracteristicamente brasileiros passam quase desapercebidos pelo crítico.

Nestes anos aparecem mais duas obras literárias brasileiras: Paulo Rónai publica, em 1940, uma seleção de poemas de Ribeiro Couto, com o título de Santosi versek ('Poemas de Santos') e o jornal Népszava publica em folhetins $O$ Cortiço, de Aluísio Azevedo, com o título de Egy brazil bérház ('Um prédio brasileiro') '17; esta tradução depois, em 1944, foi publicada em forma de livro, com o título Hangyaboly ('Formigueiro') ${ }^{18}$.

A Segunda Grande Guerra e o estabelecimento de um novo sistema político na Hungria, a chamada "construção do socialismo", indicam um câmbio de concepção na recepção e interpretação da literatura. A literatura passa a ser uma arma da luta ideológica, desta forma já não se procuram nela os valores universais e eternos, senão uma resposta mais ou menos imediata à realidade circundante. Neste novo horizonte cultural-literário,

16 Nyugat, nro 12. de 1939, Seção "Figyelö". CD-rom Nyugat 1908-1941. Egy irodalmi legenda-digitálisan.

17 “Egy brazil bérház”. Trad. por Henrik Horváth. Népszava (Budapeste), desde o nro. 233 de 1940 até o nro. 20 de 1941.

18 Esta edição de 1944 do romance (Budapeste, Anonymus) de Azevedo teve uma reduzida edição fac-similada de 30 exemplares: Aluizio Azevedo: Hangyaboly. Budapeste, Íbisz, 2002.

Gláuks: Revista de Letras e Artes - jul/dez 2020 - v. 20, n. 2 
corresponde um lugar privilegiado ao Brasil. Sendo um país, ao parecer, mais independente dos Estados Unidos do que os outros países latino-americanos, o Brasil torna-se um foco ocidental da luta contra o imperialismo. Na prensa diária e ideológica da época, ${ }^{19}$ o Brasil ocupa um lugar eminente, quase como uma frente aberta da luta do povo. A literatura, naturalmente, tinha de corresponder a esta imagem martelada, completando-a.

Por esta razão, os romances do primeiro período de Jorge Amado são bem recebidos na Hungria e seu autor torna-se um escritor favorito que tem uma presença contínua na prensa húngara. Entre 1947 e 1976 saíram 15 livros de Jorge Amado (2 no final dos anos 1940, 5 nos anos 1950, 6 nos anos 1960 e 3 nos anos 1970, não contando as inúmeras reedições) ${ }^{20}$ e foram publicadas 26 recensões críticas sobre estes $\operatorname{livros}^{21}$. Mas o que mostra ainda mais a sua difusão, como escritor politicamente comprometido, é o grande número de escritos sobre sua figura. Entre 1953 e 1975, saíram 16 artigos que diziam a respeito dele, e muitos com títulos altissonantes como: "Os eminentes soldados da paz: Jorge Amado" ou "Jorge Amado sobre o movimento da paz brasileiro e sobre seu novo romance"22.

Com esta profusão com que os romances de Jorge Amado circulavam na Hungria (com tiragens de 40 a 80 mil exemplares), não é de estranhar que até hoje o Brasil apareçanos a cores "jorgeamadianas", como observa o autor da recensão informativa sobre a

19 Esta época é chamada "os anos cinqüenta" que designa um periodo que ia de 1949 até 1956 - ano da revolução contra o sistema dirigido pelos comunistas de Moscovo - mas num sentido mais amplo compreendia os anos entre 1947 e 1960.

20 Oferecemos uma lista completa das edições das obras de Jorge Amado em húngaro (entre parenteses indicamos as edições posteriores): Terras do sem Fim (Szenvedélyek földje). Trad. por Attila Orbók. Budapeste, Káldor, 1947 (uma segunda edição com o título húngaro: Végtelen földek. Trad. por Emil Hartai. Budapeste, Szikra, 1950); Cacau (Arany gyümölcsök földje). Trad. por Emil Hartai. Budapeste, Szikra, 1949 (segunda edição: Európa, 1975); Vida de Luís Carlos Prestes, O Cavaleiro da Esperança (A reménység lovagja. Életrajzi regény Luis Carlos Prestesröl). Trad. por Emil Hartai. Budapeste, Révai, 1950; Seara Vermelha (Vörös vetés). Trad. por Marcell Benedek. Budapeste, Szépirodalmi, 1951; Jubiabá (Zsubiabá). Trad. por János Benyhe. Budapeste, Szépirodalmi, 1952; Mar Morto (Holt tenger). Trad. por Sándor Tavaszy. Budapeste, Kossuth, 1960; (segunda edição, idem, 1961, terceira edição, idem, 1973); A Morte e a Morte de Quincas Berro Dagua (Vízorditó három halála). Trad. por Lajos Boglár. Budapeste, Európa, 1961; Gabriela, Cravo e Canela (Gabriela, szegfü és fahéj). Trad. por Sándor Szalay. Budapeste, Európa, 1961(segunda edição, idem, 1975); A Completa Verdade Sôbre as Discutidas Aventuras do Comandante Vasco Moscoso de Aragão, Capitão de Longo Curso (A vén tengerész). Trad. por Sándor Szalay. Budapeste, Európa, 1963; Os Pastôres da Noite (Az éjszaka pásztorai). Trad. por János Benyhe. Budapeste, Kossuth, 1967; Dona Flor e Seus Dois Maridos (Flor asszony két férje). Trad. por János Benyhe. Budapeste, Európa, 1970; Capitães da Areia (A kikötö rémei). Trad. por Sándor Tavaszy. Budapeste, Kozmosz Könyvek, 1971; Tenda dos Milagres (Csodabazár). Trad. por András Gulyás. Budapeste, Európa, 1976.

21 Queremos notar como curiosidade que do romance A Completa Verdade Sôbre as Discutidas Aventuras do Comandante Vasco Moscoso Aragão, Capitão de Longo Curso, intitulado em húngaro A vén tengerész (' O velho marinheiro'), saído em 1963, se escreveram entre maio de outubro daquele ano 6 recensões informativas nos mais diversos órgãos de prensa. 22 "A béke kiváló harcosai: Amado Jorge”. Népszava. 30 de maio de 1953. "Jorge Amado a brazil békemozgalomról és új regényéröl”. Szabad Nép. 18 de dezembro de 1953.

Gláuks: Revista de Letras e Artes - jul/dez 2020 - v. 20, n. 2 
antologia de contos Boszorkányszombat (que emprestou o título do conto Mistério do sábado de Rui Ribeiro Couto): “Arany gyümölcsök földje ['A terra das frutas de ouro' é o título em húngaro do Cacau - nota do autor] se tornou conhecida entre nós pelos romances do escritor de fama mundial, Jorge Amado. O enorme país longínquo mais tarde foi visitado por autores de livros de viagens e emigrantes de »O Inferno verde até Porto Alegre«, como foi Lajos Kutasi Kovács."23

Um dos primeiros escritos sobre o romancista Jorge Amado é uma recensão crítica do Terras do sem fim, publicada na revista científico-ideológica do partido comunista, Társadalmi Szemle ${ }^{24}$, que determina as linhas de interpretação deste romance, e indiretamente as dos outros com estas palavras: "Jorge Amado, Pablo Neruda e os outros escritores eminentes [...] mostram uma nova cara da América Latina. Não são o exotismo, a imagem das selvas sem fim que prevalece nas obras deles, senão a luta de classes violenta na qual se trava uma batalha entre os coronéis das terras de cacau e os escravos deles."

Este tono altamente comprometido compreende-se porque se trata de um artigo de teor informativo que saiu numa revista teórica, mas as recensões das revistas literárias também incorrem neste tono politizado onde não cabe lugar a uma análise literário-estética. Um dos historiadores de literatura da época escreveu assim a raiz da 'Terra de frutas de ouro' (no original: Cacau) na revista literária intitulada Csillag da Associação Húngara de Escritores ${ }^{25}$ : "O romance de Amado é um escrito combativo, comunista. Seus heróis verdadeiros são o povo e o homem de novo quilate, proveniente do povo e lutando contra os horrores do mundo imperialista: o homem comunista."

Sob o final da década de 1950, esta imagem deformada do Brasil e de sua literatura começa a se matizar. Além de Jorge Amado, vêm aparecendo outros escritores e entre eles alguns cuja obra tem outros valores não apenas políticos. Assim saíram dois poemas de Jorge de Lima na revista de literatura mundial, Nagyvilág (fundada na época do "abrandamento" do poder totalitário ${ }^{26}$. A apresentação do poeta tem momentos pueris, por exemplo quando o

23 Lajos Kutasi Kovács, jornalista, escreveu várias obras resumindo suas experiências no Brasil. O referido, A Zöldpokoltól a Vidámkikötőig (Budapeste, Gondolat, 1972) é um dos livros do autor.

24 Ano 1950. Nro. 10: 834. O artigo é assinado com a sigla: -z. -l.

25 Koczkás Sándor: “Arany gyümölcsök földje”. Csillag. 1950. Nro. 27: 61. 26 Nagyvilág . Ano IV. Nro. 8, agosto de 1959: 1173-1174.

Gláuks: Revista de Letras e Artes - jul/dez 2020 - v. 20, n. 2 


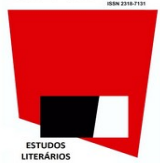

autor do artigo, Ferenc Kordás, diz: "Amou o homem trabalhador com a alma inteira" e frases parecidas que talvez eram necessárias para poder publicar os poemas do poeta brasileiro e poder apresentá-lo como um "espírito burguês, moderno, altamente exigente, atilado, progressivo". É de saber que a palavra "burguês" era quase um "palavrão" naqueles tempos.

Nas notas de viagens de um literato húngaro que em 1961 publicou as suas "Impressões do Brasil"27, depois de assistir ao congresso do PEN Clube, no Rio de Janeiro, já se encontra um tono mais equilibrado. A obra de Jorge Amado para ele já é uma fonte de informação antes sensorial que transpolitizado sobre "este mundo popular peculiar, de cujas beleza e intimidade gostei tanto como da sua rica fantasia e das suas múltiplas cores decorativas."

O guia deste literato húngaro durante sua visita no Brasil foi uma monografia: a Geografia da Fome de Josué de Castro, mas o autor tem bastante sensibilidade para descobrir e ver um Brasil multifacético, com componentes variados, entre eles a música popular brasileira de melodias melancólicas, o Carnaval (interpretado sob a influência do filme francês intitulado, Orfeu do Carnaval ) e as suas próprias impressões, colhidas da paisagem brasileira.

Com esta relativa abertura em formar opiniões subjetivas, que começava a prevalecer lentamente a partir do início dos anos 1960 na política cultural e literária húngaras, começa a se diversificar a edição de livros e a divulgação da literatura brasileira. O autor mais propagado ainda é Jorge Amado, mas em harmonia com a renovada temática de sua obra, aparecem, também em húngaro, os romances mais divertidos dele.

No terreno da edição, de um lado, se publicam obras de autores comprometidos, como as de Jorge Amado, já mencionadas, o Quarto de despejo, de Carolina Maria de Jesús ${ }^{28}, O$ ciclo do Caranguejo, de Josué de Castro ${ }^{29}$, São Bernardo e Vidas Secas, de Graciliano Ramos $^{30}$, mas, ao par deles, saem romances como $O$ resto é silêncio, de Érico Veríssimo ${ }^{31}$ e $O$

27 István Sőtér: "Brazil impresszió". Új Írás. Ano I. Nro. 8, agosto de 1961: 729-735.

28 Aki átment a szivárvány alatt. Budapeste, Kossuth, 1964.

29 Emberek és rákok. Budapeste, Kossuth, 1968.

30 Emberfarkas. Budapeste, Európa, 1962. Aszály. Budapeste, Európa, 1967.

31 A többi néma csend. Budapeste, Európa, 1967.

Gláuks: Revista de Letras e Artes - jul/dez 2020 - v. 20, n. 2 


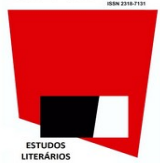

Guarani, de José de Alencar, embora este último fosse vertido para húngaro de forma abreviada, numa edição para a juventude ${ }^{32}$.

Doutro lado e de forma menos manifesta, aparecem obras da mais diversa índole, mormente para os intelectuais. Esta forma de publicação "velada", um pouco contrária à política cultural oficial, caracteriza em primeiro lugar a revista de literatura mundial Nagyvilág e algumas antologias de poesia e de prosa, para um público seleto, nas quais com obras esporádicas podiam estar presentes muitos autores de valor da literatura brasileira.

Desta forma, a poesia de 30 a 40, maiores poetas brasileiros divulga-se por antologias de poesia latino-americana, como Dél keresztje ('Cruzeiro do Sul', 1957), Fehér kövön fekete kö ('Pedra Preta sobre Pedra Branca', 1965), Kígyóölö ének ('Canto de Matar Cobras', 1973), Hesperidák kertje ('Jardim das Hespérides', 1971), Járom és csillag ('Jugo e Estrela’, 1984), onde os versos dos poetas vão acompanhados de notas biográficas e bibliográficas, assim os interessados têm ao alcance uma vasta fonte de informação da poesia brasileira.

De mesma forma, apareciam contos de Graciliano Ramos, João Guimarães Rosa, Jorge Amado em antologias da prosa latino-americana: Ördögszakadék ('Abismo de diabo', 1966), Dél-amerikai elbeszélök ('Narradores latino-americanos', 1970), Az üldözö ('O perseguidor', novelas latino-americanas, 1972).

Outro mérito da mencionada revista de literatura mundial, Nagyvilág é a informação direta ou indireta dos autores e obras, tendências e fenómenos literários, tendo em vista o interesse puramente literário ou estético. Assim, em 1958, se publica uma crítica da estreia em Budapeste d' A Raposa e as Uvas, de Guilherme de Figueiredo ${ }^{33}$, passando por alto qualquer questão política. Em 1961, a revista informa sobre a atividade de Paulo Rónai no Brasil, frisando a importância de seu trabalho no conhecimento mútuo entre o Brasil e a Hungria ${ }^{34}$. E é nas páginas desta revista que aparece um estudo sobre o romance brasileiro contemporâneo em $1962^{35}$ e um ensaio sobre o desenvolvimento da literatura latino-americana, em $1969^{36}$,

32 Máglyák az öserdőben. Budapeste, Móra, 1970.

33 Béla Mátrai-Betegh: "Két színházi este”. Nagyvilág. Ano III. Nro. 2, fevereiro de 1958: 284.

34 Albert Gyergyai: “Magyarok külföldön”. Nagyvilág. Ano VI. Nro. 10, outubro de 1961: 1566-1567.

35 Sándor Tavaszy: “A mai brazil regény”. Nagyvilág. Ano VII. Nro. 9, setembro de 1962: 1388-1391.

36 János Benyhe: "Latin-amerikai számvetés”. Nagyvilág. Ano XIV. Nro. 11, novembro de 1969: 1723- 731.

Gláuks: Revista de Letras e Artes - jul/dez 2020 - v. 20, n. 2 


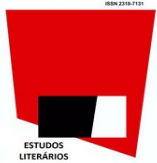

para não mencionar as resenhas sobre os livros de Jorge Amado, sobre romances como $O$ Tempo e o Vento, de Érico Veríssimo, Irmão Juazeiro, de Francisco Julião ou Dona Flor e seus dois maridos, que são já críticas onde prevalece a visão literária. $\mathrm{O}$ texto mais característico desta época é o necrólogo de Guimarães Rosa que a revista mencionada publicou em $1968^{37}$. Nele se fala na "síntese dos mágicos elementos primitivos de mundos diferentes", em "mitos de valor universal de conteúdo filosófico" e a linguagem engenhosa e estranha que o escritor forjara e que parece muito com a linguagem de James Joyce.

A partir de meados dos anos 1970, sob a influência do "boom" da literatura latinoamericana, em espanhol, relega-se para o segundo plano a literatura brasileira. Na realidade, o interesse do público diminui por estas obras brasileiras que tratam de uma forma direta os problemas políticos e sociais porque o exotismo dos autores do realismo mágico, a forte carga intelectual dos pós-modernos como Julio Cortázar e Jorge Luis Borges e a urdidura complexa dos romances políticos de autores peruanos ou mexicanos atraem mais o interesse dos leitores húngaros.

Nestes anos surgiu uma nova geração de divulgadores das letras brasileiras, com um renovado gosto literário que pretendia mostrar os rasgos característicos e essenciais desta literatura. Entre março de 1983 e 1986 teve lugar na Rádio Húngara uma série de programas, de meia hora de duração cada uma, com o título de Literaturas de América-Latina ${ }^{38}$ que ofereceu uma panorâmica das literaturas do continente no século XX, falando também dos novos e característicos fenómenos da literatura brasileira, como o Pré-modernismo e o Modernismo, a Poesia Concreta, a moderna prosa experimental e a da grande urbe, fazendo conhecer ao público nomes que antes nunca foram mencionados, como o de Oswald de Andrade, Haroldo de Campos, Rubém Fonseca, Dalton Trevisan, Ignácio de Loyola Brandão, que com a sua obra despertaram o interesse da elite intelectual. Nesta época aconteceu um momento feliz da divulgação de literatura brasileira: a publicação do Macunaíma, de Mário de Andrade $^{39}$. Este livro foi um verdadeiro êxito editorial, porque em vários meses se esgotou

37 Paulo Rónai: “João Guimarães Rosa”. Nagyvilág. Ano XIII. Nro. 3, março de 1968: 338- 339.

38 Latin-Amerika Irodalma, organizadores Vera Székács e Ferenc Pál, o primeiro programa teve lugar em março de 1983 e o último (o $\left.25^{\circ}\right) \mathrm{em}$ abril de 1986.

39 Makunaima. Trad. e posfaciado por Ferenc Pál. Budapeste, Magvetö, 1983.

Gláuks: Revista de Letras e Artes - jul/dez 2020 - v. 20, n. 2 
a tiragem de dez mil exemplares. O público, ávido do exotismo, antes tão repreendido, devorava o livro que foi apresentado como um grande acontecimento cultural pelos programas culturais da rádio e da TV e nas recensões ${ }^{40}$ se frisava a feliz mistura do intelectual e popular, a força primitiva desta obra:

O Macunaíma é a consequência da capitalização latino-americana irregular e tormentosa, da americanização que abraça aplastando a versatilidade étnica (linguística, folclorística e etnográfica), de múltiplas cores e raízes e dos excessos intelectuais amotinados e revoltoso, escreve entusiasmado o crítico $^{41}$ que no título da sua recensão menciona Macunaíma como "Kalevala artificial de zona tórrida".

A edição de Nove Novena de Osman Lins ${ }^{42}$ mostra uma certa perplexidade provocada por este câmbio de paradigma no gosto dos divulgadores. O autor do posfácio, ilustre estudioso e tradutor, um tal indeciso, evoca, como ponto de referência a obra nordestina de Jorge Amado, os ambientes do sul de Veríssimo e as fortes cores mineiras de Guimarães Rosa, e lamenta que estes enérgicos elementos linguísticos faltem na obra de Osman Lins. Já aqui se manifesta uma cisão, divergência entre os gostos da velha e da nova geração. Aconteceu, por exemplo, no decorrer duma palestra, transmitida pela rádio, entre o tradutor de Jorge Amado, János Benyhe, e o autor deste trabalho, que aquele pôs em confronto com a moderna literatura da grande urbe aquela literatura classicizante, pastoril que se cultiva nos recantos ocultos do Brasil, conservando valores eternos, frisando os valores deste e criticando aquele. Este princípio, que se mantém quase intato desde a antologia de 1939, Mensagem do Brasil, igualmente predomina numa antologia de $1984^{43}$, até agora a maior antologia da poesia latino-americana. Surpreende-nos que a lista dos poetas modernos seja quase igual à da

40 Mihály Szalontai: "Makunaíma (Mário de Andrade könyve). Magyar Nemzet, 14 de março de 1984. Pál Bodor: "Forróégövi mü-Kalevala (Mário de Andrade Makunaima-forditásáról)”. Élet ésIrodalom, 27 de abril de 1984.). Oszkár Csertöi: "Makunaima (Mário de Andrade regénye)”. Új Tükör, 20 de maio de 1984.

41 Pál Bodor.

42 Kilenc kilenced. Trad. por Judit Xantus e posfaciado por János Benyhe. Budapeste, Európa, 1985.

43 Járom és csillag ('Jugo e estrela'), seleção, prefácio e notas por János Benyhe. Budapeste, Kozmosz, 1984. Na antologia aparecem poemas de Mário de Andrade, Augusto dos Anjos, Manuel Bandeira, Olavo Bilac, Raul Bopp, Geir Campos, Ronald de Carvalho, Vicente de Carvalho, Francisco Antônio de Carvalho Júnior, Antônio de Castro Alves, Raimundo Correia, Bernardino da Costa Lopes, João da Cruz e Sousa, Luís Delfino, Teófilo Dias, Carlos Drummond de Andrade, Ascenso Ferreira, Antônio Cândido Gonçalves Crespo, Alphonsus de Guimaraens, Sebastião Cínero dos Guimarãens Passos, Luís José Junqueira Freire, Jorge de Lima, Joaquim Maria Machado de Assis, Gregório de Matos, Cecília Meireles, Vinícius de Morais, Alberto de Oliveira, Rui Ribeiro Couto, Augusto Frederico Schmidt

Gláuks: Revista de Letras e Artes - jul/dez 2020 - v. 20, n. 2 
seleção de meio século atrás (Ascenso Ferreira, Raul Bopp e Vinícius de Morais são apenas os nomes novos) e assim mesmo há muitas coincidências nos poemas escolhidos. Outro livro desta índole, entre o passado e o presente, foi a antologia Boszorkányszombat, em 1986, um livro de $\operatorname{contos}^{44}$ que iam desde Pai contra mãe, de Machado de Assis, até Feliz aniversário, de Clarice Lispector - uma seleção cuidadosa, com notas bibliográficas que foi recebida com entusiasmo da parte dos críticos, talvez porque saísse ao mesmo tempo que a edição em húngaro de $A$ escrava Isaura ${ }^{45}$, quer dizer, no auge do interesse do público pelo Brasil, suscitado pela telenovela feita com base do romance de Bernardo Guimarães. Lendo a recensão destes dois romances, vale a pena meditar sobre esta frase da mesma: "A maioria dos contos mostra gente lutando com seu fado, gente que quase nunca triunfa, o mundo de vilas e casas grandes, um país de tempo parado, estancado em cerimonias [grifado nosso - F. P.].” Esta visão do Brasil que formou dele um intelectual húngaro nos meados da década de oitenta é bastante estranha, por ser fora do tempo, e explica aquele fenômeno curioso de os idosos telespectadores húngaros quererem reunir dinheiro para remir Isaura da escravatura.

Como fica claro de tudo isso, já era altura renovar a imagem do Brasil, porque o apego aos prejuízos e noções dos períodos anteriores não criava apenas problemas no conhecimento (atualizado) da literatura brasileira, senão também irradiava imagens de um mundo caduco, parado, de certa forma atemporal, se pensarmos no pitoresco das imagens baianas de Jorge Amado, entretanto que na prensa falava-se já do dinamismo da "maravilha económica brasileira".

No final da década de noventa se alteraram bruscamente os hábitos de leitura e o gosto do público húngaro. Ao par da propagação cada vez mais arrogante dos programas televisivos e a divulgação das séries televisivas, ia diminuindo o gosto pela leitura. O grande público,

44 Boszorkányszombat (Mistério de sábado), sel. e notas de Paulo Rónai, trad. por István Bárczy, Éva Faragó, Ferenc Pál, Paulo Rónai, Eszter S. Tóth, Ervin Székely. Budapeste, Európa, 1986. Na antologia se encontram contos de Machado de Assis: Pai contra mãe, Lima Barreto: O homem que sabia javanês, Monteiro Lobato: O comprador de fazendas, Mário de Andrade: O peru de Natal, Aníbal M. de Machado: O ascensorista, Rui Ribeiro Couto: Mistério de sábado, João Alphonsus de Guimaraens: Eis a noite!, Alcântara Machado: As cinco panelas de oiro, Luís Jardim: Paisagem Perdida, Carlos Drummond de Andrade: Beira-rio. Orígenes Lessa: Roteiro de Fortaleza, Marques Rebelo: Caprichosos da Tijuca, João Guimarães Rosa. A terceira margem do rio, Aurélio Buarque de Holanda: O chapéu de meu pai, Rachel de Queirós: A donzela e a moura torta, Lygia Fagundes Telles: Venha ver o pôr do sol, Oto Lara Resende: O retrato na gaveta, Clarice Lispector: Feliz Aniversario.

45 Isaura, a rabszolgalány. Trad. por István Bárczy. Budapeste, Európa, 1987.

Gláuks: Revista de Letras e Artes - jul/dez 2020 - v. 20, n. 2 


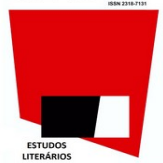

outrora leitor ávido dos romances de Jorge Amado, abandonou a literatura de valor, e os novos leitores intelectuais, que aprendiam ler com os autores pós-modernos, requeriam leituras mais sofisticadas do que o realismo simples dos autores anterior- e tradicionalmente publicados. Desta forma, e como resultado de certo complot de intelectuais novos, saiu em 1990 o romance Zero, de Ignácio de Loyola Brandão ${ }^{46}$ que a crítica recebeu ${ }^{47}$ como informação maravilhosa de um mundo caoticamente moderno.

Ao ver e ler as obras dos autores brasileiros surgidos na década de sessenta, os literatos da velha estirpe torciam o nariz e diziam que estas obras "não são literatura". Desta forma, por exemplo, os primeiros contos traduzidos de Dalton Trevisan, Rubem Fonseca e autores afins, não tendo outros foros, foram transmitidos por programas radiais e publicados numa revista de literatura erótica ${ }^{48}$. Aconteceu assim quando fizemos uma escolha de contos brasileiros para o número comemorativo dos 500 anos do Brasil da revista da Associação Húngara dos Escritores, intitulada Magyar Napló ${ }^{49}$ : os redatores da revista ainda opinavam que a brasileira é uma literatura simples, abeirando a literatura de cordel. No entanto, com a mudança de gostos, mesmo os foros mais exigentes da literatura, como a revista Nagyvilág, abriram as portas à atual literatura brasileira $^{50}$, e foram publicados, para um público muito seleto, poemas de dois representantes da poesia concreta, Haroldo de Campos e Décio Pignatari. ${ }^{51}$ Estes livros receberam um reconhecimento crítico $^{52}$ no qual ficou constatada a independência criativa da literatura brasileira: “A formação da [...] poesia concreta no início

46 Zero. Trad. por Ferenc Pál. Budapeste, Európa, 1990.

47 Imre Wirth: "Ignácio de Loyola Brandão - Zero". Élet és Irodalom, 29 de março de 1991: 11.

48 Dalton Trevisan: "Curitiba bajnoka" (Míster Curitiba). Trad. por Ferenc Pál. Erato, ano II. Nro. 1, janeiro de 1989. Rubem Fonseca: "Együttlét és szembenállás" e "Az álom anyaga" (O encontro e o confronto, A matéria do sonho.) Trad. por Ferenc Pál. Erato, ano II. Nro. 2, março de 1989. Dalton Trevisan: "Szüzi csók a szerelem katedrálisában” (Beijo virgem na catedral do amor). Trad. por Ferenc Pál. Erato, ano II. Nro. 2, março de 1989.

49 Magyar Napló. Ano XII. Nro 3. julho-agosto-setembro de 2000: 28-57. Na seleção aparecem contos e escritos de Rubem Fonseca, Ivan Lessa e Dalton Trevisan. Cristóvão Tezza, João Silvério Trevisan, Ignácio de Loyola Brandão.

50 Esta revista publicou no seu número de abril de 1991 (ano XXXVI. Nro. 4) o conto "Bolívar" de Victor Giudice, cujo outro conto, "Salvador a Lamasban vacsorázik" (Salvador janta no Lamas) foi publicado no número de "Inverno" 1991-92, da revista literária POLISZ. E no número de agosto de 1992 (ano XXXVII, nro 8), publicou dois contos de Dalton Trevisan, numa seleção de literatura erótica.

51 Haroldo de Campos: Konkrét versek ('Poemas concretos'). Trad. por András Petöcz e Ferenc Pál. Seleção, prefácio e notas por Ferenc Pál. Budapest: Íbisz, 1997. Décio Pignatari: Vers-gyakorlatok ('Exercícios de poesia'). Trad. por András Petöcz e Ferenc Pál. Seleção, prefácio e notas por Ferenc Pál. Budapest: Íbisz, 1997.

52 Szkárosi Endre: "A nyelv végének barlangrajzai" ('Pinturas rupestres do fim da língua'). Élet és Irodalom, 27 de agosto de 1999: 14 .

Gláuks: Revista de Letras e Artes - jul/dez 2020 - v. 20, n. 2 


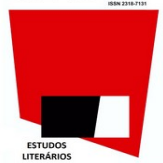

dos anos cinquenta não é o primeiro exemplo de que na periferia da zona cultural euroamericana aparecem uma nova linguagem e uma expressão autênticas que correspondem às demandas intelectuais desta zona."

Nas últimas duas décadas, o Brasil através de sua literatura estava presente em três palcos. De um lado, se tinham multiplicado as telenovelas na programação das TV-s húngaras. E não é uma contradição que falamos neste estudo sobre este género televisivo, porque na realidade o consideramos uma forma da difusão ou pelo menos da propagação da literatura aquando adaptações de uma obra literária, como, por exemplo, no caso de $O$ Tempo e o Vento, baseado na trilogia de Érico Veríssimo. Outro caso, é o fenómeno de Paulo Coelho, cuja popularidade ou podemos dizer, culto,, começou em 1993 com a publicação em húngaro de $O$ diário de um mago, e, nas últimas duas décadas, saíram 22 livros do autor que, visitando Budapeste em 2005, na altura do Festival do Livro, recebeu a Budapest Nagydíj ('Grande Prémio Budapeste'). A vaga da popularidade de Coelho durou uns 15 anos, mas nos últimos tempos escasseiam, pelo menos entre jovens, os seus leitores, apesar de que continuam saindo suas obras em húngaro, como, ultimamente, o Hippie, em 2018.

Houve uma tentativa de reintroduzir no mercado de livro os romances de Jorge Amado. Nos anos 2008-2010, foram publicados em novas edições, Dona Flor e Seus dois Maridos, Jubiabá e O Gato Malhado e a Andorinha Sinhá (Galád Kandúr és fecske kisasszony $)^{53}$, mas passaram quase despercebidos. Mas, de repente, foi um êxito editorial o romance de Chico Buarque, Budapeste, que saiu em 2005. ${ }^{54} \mathrm{O}$ elenco intelectual reduzido recebeu com gosto a iniciativa da editora PRAE.HU, que, em 2007, editou uma antologia bilíngue, intitulada Antologia do moderno conto brasileiro (A modern brazil elbeszélés, antológia) cuja seleção, introdução e a apresentação dos autores foi feita pelo embaixador José A. Lindgren Alves ${ }^{55}$. As reflexões críticas receberam esta antologia com satisfação

53 Budapeste, Európa, 2008 e 2010, L'Harmattan, 2008 respectivamente.

54 Budapeste, Athenaeum 2000, 2005. Trad. Por Ferenc Pál

55 Trad. por Péter Borbáth, Mária Magdolna Demeter, Veronika Gergely, Réka Karvaly, Lenke Kovács, Lilla Lencsó, Laura Kulács, Dóra Nagy, Dániel Levente Pál, Ferenc Pál, Zsombor Szabolcs Pál. Na antologia se encontram contos de Antônio de Alcântara Machado: Apólogo Brasileiro sem Véu de Alegoria, Rachel de Queirós: Tangerine-Girl, Guimarães Rosa: Duelo, Antônio Fraga: Clave de Sol, Clarice Lispector: Feliz Aniversário, Fernando Sabino: O Homem Nu, Otto Lara Resende: O Elo Partido, Autran Dourado: Três Coroas, Lygia Fagundes Telles: A Estrutura da Bolha de Sabão, Ignácio de Loyola Brandão: O Homem Que Viu o Lagarto Comer Seu Filho, Márcio Souza: A Caligrafia de Deus, Rubem Fonseca: O Cobrador, Adélia Prado: Mistério Maior, Raduan Nassar: O Ventre Seco, Moacyr Scliar: Zap, Dalton Trevisan: O Vampiro

Gláuks: Revista de Letras e Artes - jul/dez 2020 - v. 20, n. 2 


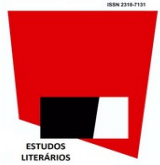

porque, segundo rezavam, o mesmo deu entender ao público que além das telenovelas e novelas de Paulo Coelho existe uma literatura de quilate no Brasi1 ${ }^{56}$. Entre os últimos momentos da divulgação das letras brasileiras na Hungria havemos de mencionar o número de abril de 2014 da revista da literatura mundial, Nagyvilág, na qual saíram obras de quase duas dúzias de contistas e poemas de 6 poetas. ${ }^{57}$

Laura Lukács, reconhecida tradutora, em 2016, levada por um interesse requintado, traduziu duas novelas de Raduan Nassar: Um copo de cólera e Lavoura arcáica ${ }^{58}$. Um ano depois, o PEN Clube Húngaro outorgou o 'Grande Prémio de Poesia Janus Pannonius' a Augusto de Campos, e para esta ocasião foi publicada uma seleção da obra poética dele com o título: Hangszóképversek ${ }^{59}$. E temos que mencionar a recente grande empresa da Editora de Budapest, Magvető Könyvkiadó que editou Todos os contos de Clarice Lispector ${ }^{60}$, e a $A$ hora de estrela dela ${ }^{61}$.

Que poderíamos dizer a título de conclusão? Talvez, que se tem criado uma nova geração de tradutores que com sensibilidade para as novas tendências literárias será capaz de divulgar as novas letras brasileiras, atualizando nosso conhecimento e preenchendo os vácuos que ainda existem. Assim, neste ano se espera - comemorando o centésimo aniversário do nascimento do poeta - a tradução e publicação de poemas de João Cabral de Melo Neto, a comemoração dos 100 anos da Semana de Arte Moderna, com tradução, talvez, da Pauliceia Desvairada, de Mário de Andrade. Não podemos não fazer uma referência, nestes dias

de Curitiba, Márcia Denser: Hell's Angels.

56 Ver a crítica: http://ekultura.hu/2008/02/01/a-modern-brazil-elbeszeles-antologia

57 Trad. Por Bálint Urbán, Zsombor Szabolcs Pál, Viktória Nagy, János Lackfi, Ferenc Pál, Zsófia Pilhál, Veronika Gergely, Péter Borbáth, Laura Lukács, György Jánosházy, Lenke Kovács. Os contos traduzidos: Márcio Barbosa: Viver outra vez, Fernando Bonassi: 15 Cenas de descobrimento de Brasis e Corações vagabundos, Ignácio de Loyola Brandão: Obscenidades para uma dona-de-casa, Myriam Campello: Olho, Maria Colasanti: A nova dimensão de escritor Jeffrey Curtam, Márcia Denser: O vampiro da Alameda Casabranca, Autran Dourado: Os mínimos carapinas do nada, Rubem Fonseca: Feliz Ano Novo e Passeio Noturno, Clarice Lispector: Felicidade clandestina, Dimas Carvalho Muniz: O manuscrito, Raduan Nassar: Pelas três da tarde, João Ubaldo Ribeiro: Jingle bels, jingle bels, Sérgio San'Anna: Estranhos, Moacyr Scliar: A balada do falso Messias, Carlos Sussekind: O anti-Natal de 1951, Antônio Torres: Por um pé de feijão, João Silvério Trevisan: Dois corpos que caem. E poemas dos poetas: Álvaro Álves de Faria, Cesar Leal, Mariana Ianelli, Marco Lucchesi, Vinicius de Moraes,

58 Egy pohár harag és Köbe vésve, Jelenkor.

59 Poemas 'Verbivocovizuais'. Magyar Pen Club. Sel. Ferenc Pál. Trad. Tibor Zalán, Géza Szőcs, Endre Szkárosi, Dániel Levente Pál, Ferenc Pál. Postf. Enikő Bollobás

60 Minden történet, Budapeste, Magvetö, 2018. Trad. Ferenc Pál, Laura Lukács, Mónika Bense, Réka Dorcsák 61 A csillag órája. Budapeste, Magvetö, 2019. Trad. Mónika Bense.

Gláuks: Revista de Letras e Artes - jul/dez 2020 - v. 20, n. 2 
GLÁUKS

posteriores da quarentena de mais de dois meses, a uma atualidade, que talvez seja inadequada a um estudo deste tipo: dado que a esfera editorial, semelhantemente aos outros setores da economia, tem sofrido bastantes perdas, pode-se que haja menos possibilidade de publicar obras de valor literário, assim a divulgação da literatura brasileira torna-se mais difícil, mas este vácuo talvez fosse preenchido por uma nova revista de literatura on-line, intitulada 1749.hu, que é continuadora das tradições da várias vezes mencionada Nagyvilág.

Gláuks: Revista de Letras e Artes - jul/dez 2020 - v. 20, n. 2 